\title{
MANAGEMENT OF KNOWLEDGE MODELS USING INFORMATION TECHNOLOGY
}

\author{
Petriashvili Lily, Professor, Georgian Technical University, Tbilisi, Georgia \\ Gogilidze Emeliane, Asist. Professor, Georgian Technical University Tbilisi, Georgia
}

DOI: https://doi.org/10.31435/rsglobal_conf/25042021/7525

\begin{abstract}
The topics of implementing methods of information technology as one of the effective and important methods are discussed for organizational and institutional management purposes. Information technology allows a new knowledge to be discovered which is an important and effective way for the management of organizational processes in order to maintain competitive edge.

In today's competitive and globalization world, the main challenge for organizations remains to be defining customer-oriented strategy where knowledge and its management is an important factor. Recently active works is being conducted for establishing and developing effective models of knowledge management where information technology plays an important role. Generally, information system is a means of collecting and creating new knowledge existing between different individuals/structures using information technology. It describes instruments of knowledge management that allows collaboration and communication between parties involved in business processes. Knowledge management includes facts, data and models of different types which exist in physical and electronic information depository.
\end{abstract}

Keywords: knowledge management, explicit knowledge, SECI model, knowledge assets, BI model, pyramid to wisdom \& the DIKW.

Main part. Knowledge management is defined as a means of creating, collecting, sharing and using static knowledge in business processes. There is also an opinion that knowledge management is a process of obtaining information from competent people that is used in making decisions in organizational processes. Despite differing views, both have something in common which is utilizing knowledge existing in an organization to get competitive edge in the market. A constant flow of knowledge in an organization, using modern technology and right methods of management are constitute a checklist of things managers and investors prioritize.

In order to discover new knowledge, it must be constantly renewed. With the passage of time knowledge does not increase on its own. Like money does not increase in amount without investing and with time it loses its buying potential, so does knowledge as well. It needs constant sharing, acquisition and exchange in order new knowledge to be created. The increase of tactical knowledge is possible through its socialization. Knowledge has a life-cycle of four different phases. They are the following: socialization, internalization, externalization, and unification [1].

Socialization is a face-to-face information sharing through discussion during which knowledge is passed from one person to another. An additional benefit of this phase is an opportunity of viewing knowledge from a different angle during interaction. Externalization phase implies verbalized sharing of practical knowledge. This phase is considered the phase of creating knowledge and discovering new processes. The medium for sharing practical knowledge can be words, conversation, writing, photos, video or music which impossible to convey without using information technology. It is important for explicit concepts to be systematized using physical and electronic means. Internalization means teaching without words and conversation. In this case social values and ideas are conceived by individuals as their own. Unification is a simple form when new knowledge is created by unification of codified knowledge resources [2]. The four different phases are parts of one whole process which represents a model of creation of knowledge.

Research methods. The most optimal method of knowledge management and sharing is its automatic management and targeted sharing. This means that knowledge management system should be able to manage different processes at different levels. Employees should have an opportunity to fulfill their responsibility based on their successful experience. This in turn may cause new processes in knowledge which will enable the employee to determine new parts of the processes or add new subprocesses on their own. In development of work management system, organizational (institutional) memory plays an important role.

Organization memory keeps information about organization products and services. This helps in accumulating practical knowledge. The building of corporate memory is possible through nonstructural methods which does not cost an organization much money. But this type of repository often contains 
unnecessary information. Therefore, it is necessary to filter data accumulated in information repository often. Information engineers have a different approach who base the creation of corporative knowledge system on expert systems. Replenishment of the information in in corporative memory should be done using hypertexts. This means describing processes that take place at different levels in an organization. For obtaining information about each process easily, hyperlinks connected to keywords will be used. Knowledge engineers will be responsible for placing information in information repository. They will place information relevant to solving a concrete problem and practical issues. When placing information in an information repository it is necessary to determine the purposefulness and credibility of the information. Explicit knowledge often masks real problems, which may hinder organizational processes. Thus, the information contained in the database will be adapted to organization stakeholders. Rösner et all consider knowledge engineering a source of motivation of replenishing organizational memory. Initially, it is necessary to fill information about the product of an organization. They show how to create explicit knowledge which will be integrated in new explicit knowledge in the future. This will develop tactical knowledge. All of these will be integrated in documents and utilize needed time with purpose during the execution of transactions in the organization in smart contacts [3] as well during the execution of different operations. Obtaining information from an information repository should be quick. For this purpose, the information should be described properly and be connected with hyperlinks. The information system should be available to the management as well as to lower rank employees. Replenishing of the institutional memory of an organization is not possible without having appropriate software support which is based on three important factors; these are: IT infrastructure which executes database management, document management and support of business processes. These factors constitute corporate memory architecture which lays the foundation for the development of artificial intelligence.

One of very important issues in the knowledge management are process-oriented models of different structure and type. Utilizing these, users have an opportunity to use recommendations and experience oriented on valid and qualified knowledge which are adapted to different strategy. The given models integrate knowledge obtained from different sources, which creates a united space of business decision management in real time from where business processes are managed considering appropriate skills, technology and experience [4].

Knowledge management models assist organizations in properly defining their work strategy to be adapted to outer factors and take account of client requirements in full. In order to purposefully utilize knowledge resources, it is important for a company to consider models of different types and adjust to an appropriate model corresponding to the specifics of the company. At first stage, to choose an effective model of knowledge management, it is necessary to determine what we know, how we know, why we know, who knows, when and from where he/she knows. After finding answers to these questions, we start determining an effective model of knowledge management. Let's consider a few models that help users to make an effective and optimal decision during the management of business processes.

SECI model of knowledge management (Solar Energy Corporation of Indiaolar Energy Corporation of India) is a model of knowledge creation process which ensures the formation of an effective system of knowledge management process and Knowledge Assets (the specific resources of a company that contributes to creating a valuable firm. For knowledge creation it consists of input, output and moderation factors). All three elements of Knowledge Assets are connected with other additional organic and dynamic elements. This model represents a spiral of knowledge creation which is connected to explicit and tactical knowledge (fig. 1) [6].

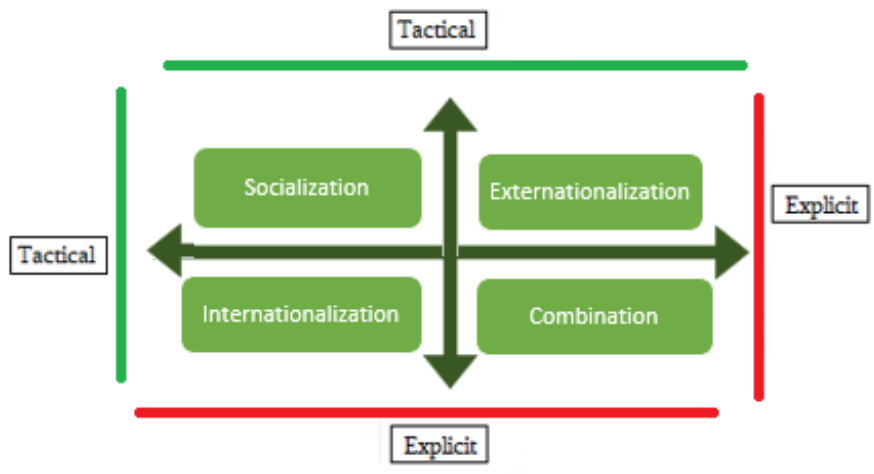

Fig. 1. 
Tactical knowledge is mainly dependent of person's emotional and sensory experience and actions. The extent of personality is formalized in tactical knowledge.

Explicit knowledge encompasses knowledge encoding and encodes knowledge. This kind of knowledge is expressed numerically and verbally. This type of knowledge forms similar to scientific knowledge.

Conceptual model of SECI (Southeast European Cooperative Initiative) knowledge encompasses the process of creating four types of knowledge. They are: socialization, which is focused on interaction of tactical knowledge where the collection of knowledge is done through interaction, observation and analysis; externalization, which ensures the development of tactical knowledge where prototypes are created by unifying different elements of explicit knowledge; internalization, which uses tactical knowledge for the creation of explicit knowledge. These boost the generation of innovative ideas [2].

Knowledge life cycle or organizational knowledge encompasses the results of knowledge production. Knowledge production is carried out using knowledge life cycle model which is a comparatively new model. This model implies knowledge creation that has a structure similar to business management. Stimulation of innovative ideas is dependent of knowledge life cycle. The formation of organizational knowledge has several phases which are shown of fig. 2:

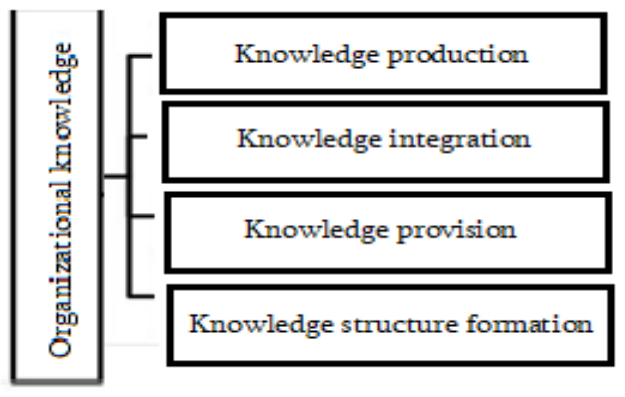

Fig.2.

Knowledge production. Knowledge production is influenced by factors such as group or individual knowledge. Before sharing knowledge, it is important to assess the validity of the information and specifics of organizational knowledge. Knowledge production is possible through processing knowledge inside organization as well as using knowledge from outside sources.

For knowledge integration it is necessary to integrate knowledge obtained through organizational knowledge production. This method involves the development of email, search instruments, methods of teaching and sharing within an organization. Organizational documents are actively used in this process. It is possible to introduce this model electronically as well as nonelectronically. Its users are the employees of an organization.

The Capability Maturity Model describes five evolutionary steps which governs organizational processes. Initially this model was created for the development of software programs for the organization. It was used in military studies. It consists of five levels and each level is oriented towards the development of organizational processes (fig.3) [6].

The first level is chaotic, does not contain written-out processes and is not adapted to the environment;

At the second level processes repeat in order to define corrected results after implementing concrete processes; processes;

At the third level all processes are documented. There are defined, standardized and integrated

At the fourth level, the processes are managed according to pre-determined data. The management is conducted through processes identified and adapted to particular projects. The development of management processes takes place at this level.

At the fifth level the development of effective process of organization management continues. Here the piloting of new ideas and technologies take place by using feedback. The management of organizational processes happens using this model, which helps in managing the knowledge acquired in real time. In the future, it will contribute to optimizing new ideas and technologies [7]. 


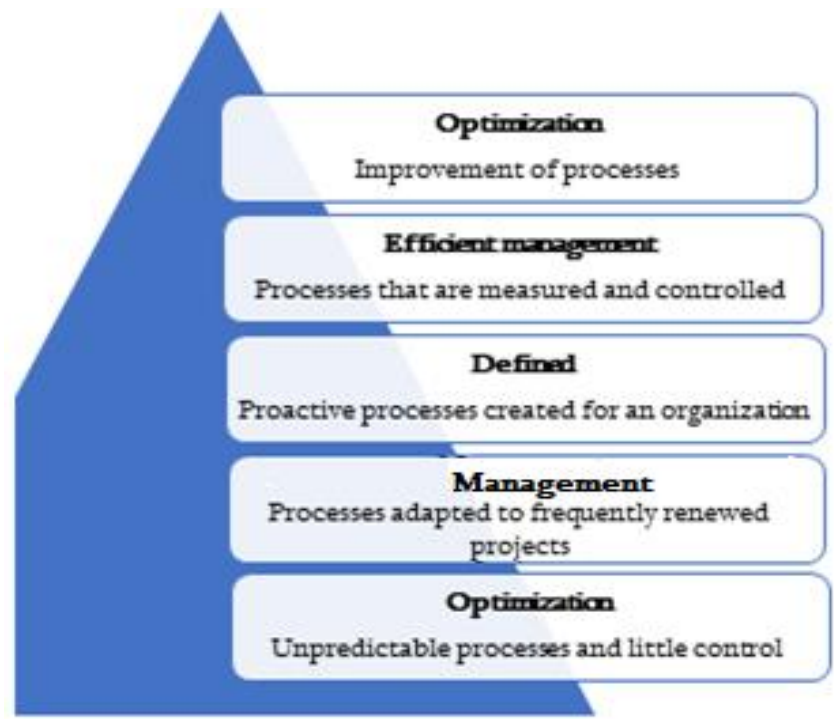

Fig.3.

The aim of Business Intelligence Model is information management system to make business decisions to enable knowledge management. Proper handling of business processes requires having corresponding skills, technologies and experience. Business intelligence (BI) supports the kind of system that helps the company to quickly make a decision. Using this system an organization will be able to develop a new business initiative adapted to customer requirements and needs in real time analyzing real data. BI includes system monitoring, information collection, reporting, analysis and production. It utilizes different strategies in the process of organizational management. This model can be introduced in organizations with different strategy.

BI includes: creation of system for organizational departments to work as a united team to fulfill the main vision of the organization; using high quality technologies for data management, and using different forms for organization departments working together for the purpose of business development (fig. 4).

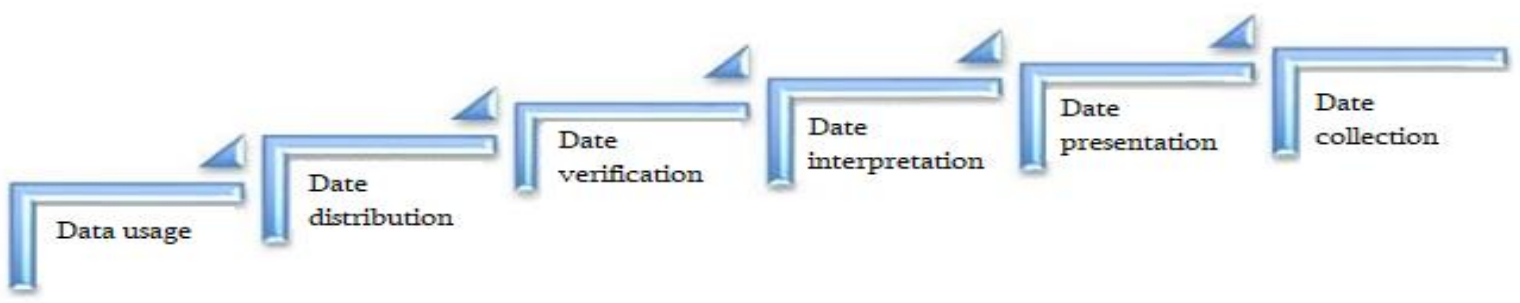

Fig.4.

Johari Window model helps individuals and organizations to increase and develop knowledge on their own. It allows for making changes in working groups according to business context. It uses corporative parameters for corporative assignments. Communication between business participants is vitally important component for the success of an organization. Every manager and leader should create an environment where employees trust each other and mutually share information. Johari Window is an information processing model which can represent two matrices in two individuals. This model implies interaction between two sources of information which work for themselves and for each other. Both matrices are an interpersonal space which corresponds to the elements of information processing process characteristic of each region. Fig. 5 shows a characteristic structure of aforementioned model. 


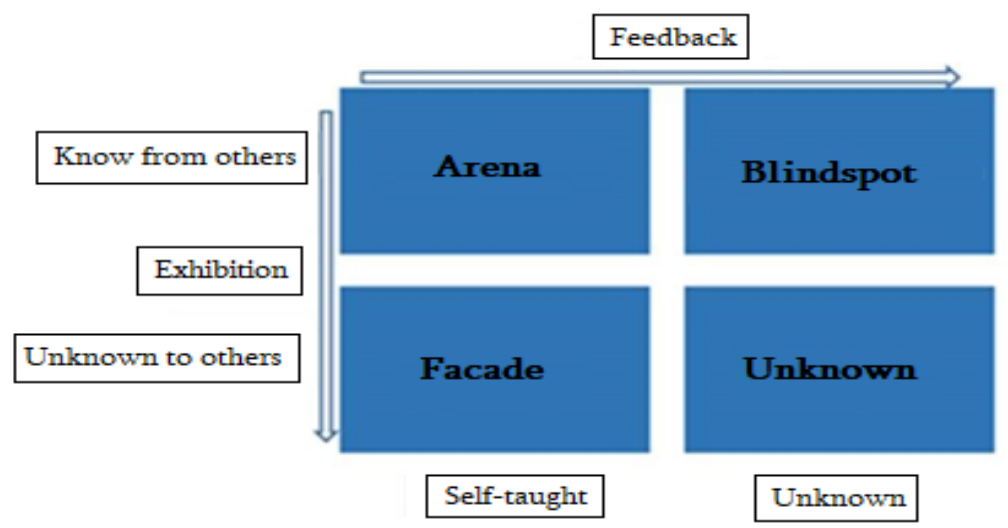

Fig.5.

Arena square is a space where information is shared both ways. In this space, an individual works for himself. To increase his productivity, he works with other co-workers and receives information about their knowledge and experience, then uses it for personal knowledge and experience development. The more participants in this space the better the result [7].

Blindspot - this square shows information which can be unknown for certain people but is a common knowledge for other employees. This is explicit knowledge which is unknown for individuals with implicit knowledge;

Facade - square represents the knowledge of such information that is accessible only for certain employees and is inaccessible for other persons. This is company's confidential information;

Unknown square contains unlimited information. It takes part in the formation of the three frames, which is actively used in the management of input chain [8].

Johari Window summary: public information is available to all parties; personal information is accessible only to certain clients but it is inaccessible to design group; blind information is only accessible to design group; as for unknown information, it is not accessible to any party.

Pyramid to Wisdom \& the DIKW (Data, Information, Knowladge, Wisdom) Model: Depending on different requirements, information may be formed differently. The presentation of information may depend on the type of question like What? How? Where? When? Pyramid Model is based on ultimate knowledge management model such as DIKW (data, information, knowledge, wisdom). Companies as famous as for example BMC use software based on practice-based system model. Fig. 6 shows the structure of the model [9].

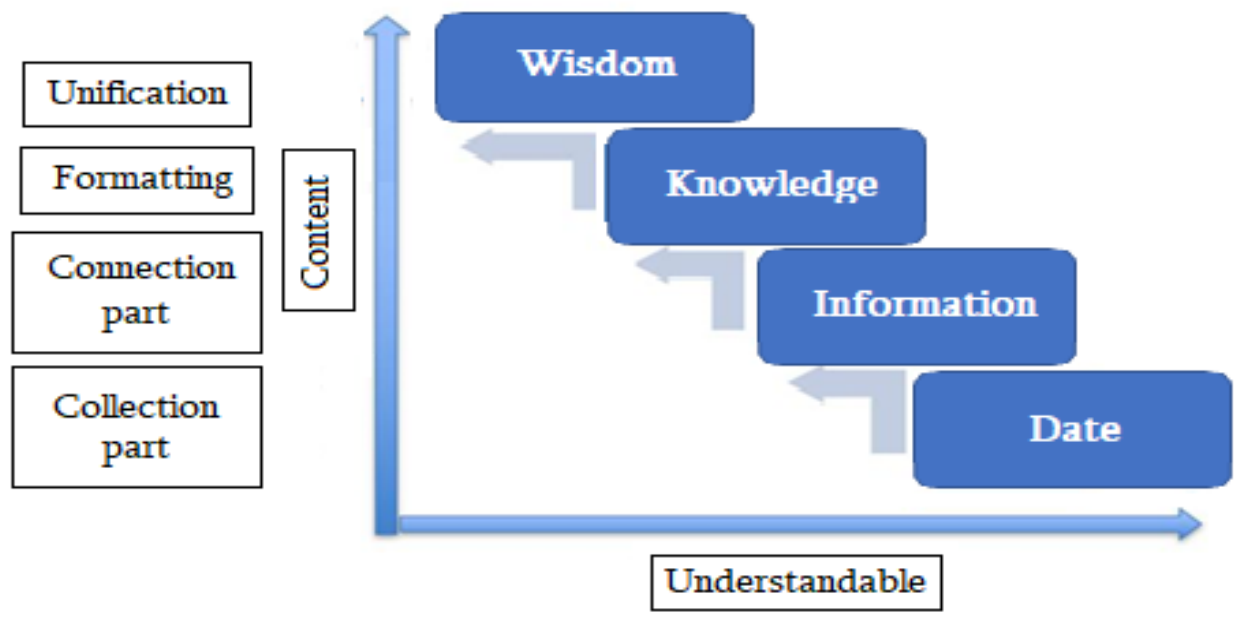

Fig. 6. DIKW model

DIKW model uses data, knowledge, information and wisdom models for making organizational decisions.

Conclusions. The movement and proper management of knowledge enables an organization to maintain balance of intellectual capital in the form of non-material assets. Non-material assets are 
the competence of employees, internal structure of an organization, patents, own models, concepts/processes, administration system, IT infrastructure, outer structure of an organization, good relations with clients and suppliers, brand, trademarks and reputation. In knowledge management, using of information technology plays an important role as it allows the companies to acquire the desired knowledge and share it with purpose in automatically managed schedule. Considering everything discussed, companies develop methodology of knowledge audit which guarantees intellectual balance being published for everyone which contributes to transparency and determining reliability criteria for partnership. The presented knowledge management models help organizations correctly define their working strategy and plan busines processes and be adapted to external factors where customer requirements will be taken into account in full.

\section{REFERENCES}

1. Kamani A., Hundewale N. (2016). Technology framework for knowledge activity: a systems thinking approach. 2011 3RD IEEE International Conference on Information Management and Engineering, Presented at the 2016 3RD IEEE International Conference on Information Management and Engineering, Zhengzhou, China, IEEE Computer Society.

2. Arif M. Egbu, C. Alom, O., Khalfan M.M.A. (2016). Measuring knowledge retention: a case study of a construction consultancy in the UAE, Engineering, Construction and Architectural Management, 16(1), 92-108

3. Doborjginidze G., Petriashvili L. Inaishvili M. "Improve Efficiency and Reliability of Supply Chains Using Smart Contracts" (2020) Improve Efficiency and Reliability of Supply Chains Using Smart Contracts. $\begin{array}{llllll}\text { International Academy Journal } & \text { Web (50). }\end{array}$ https://doi.org/10.31435/rsglobal_wos/30122020/7261 [CrossRef]

4. L. Petriashvili, D. Kapanadze, T. Zhvania "Process Management in Warehousing Logistics by Means of Rfid Automated System" Journal of Multidisciplinary Engineering Science Studies. (ISSN: 2458-925X) 2017 http://jmess.org/index.php/vol-3-issue-3 1502-1506. [CrossRef]

5. https://www.emeraldinsight.com/doi/abs/10.1108/13673270610670885

6. http://www.jmess.org/wp-content/uploads/2017/03/JMESSP13420305.pdf

7. Knowledge Creating Process, SECI Model http://www.allkm.com/km-basics/knowledgeprocess.php

8. Doborjginidze G., Petriashvili L. "Improving Efficiency of Inventory Identification System" European Science Review, Issue 1-2/2020. DOI: https://doi.org/10.29013/ESR-20-1.2-84-88

9. Nonaka's Knowledge Creation framework http://www.cyberartsweb.org/cpace/ht/thonglipfei/nonaka_seci.html 